\title{
O Trabalho Interdisciplinar no Contexto da Exclusão
}

The interdisciplinary practice in the exclusion context

Resumo:O presente artigo apresenta um programa de intervenção psicoeducativo e sócio-cultural com crianças e adolescentes em situação de risco. Discute-se um modelo de atendimento em rede, através da compreensão interdisciplinar que propõe atuação em diferentes níveis: atendimentos clínicos, oficinas psicoeducativas e de teatro. Percebe-se ainda que a instituição, enquanto conjunto de regras, a equipe de profissionais, enquanto figuras modelares e o grupo, enquanto oportunidade de pertencimento, possibilitam a inscrição do adolescente em um processo de trocas intersubjetivas, promovendo a regulação de novas relações e possibilidades de resgate e apropriação de sua história subjetiva.

Palavras-Chave: Adolescentes, situação de risco, interdisciplinar, exclusão.

Abstract: This article presents a psychoeducative, social and cultural intervention program focusing children and adolescents in situations of risk. It is discussed a model of attention by means of an interdisciplinary comprehension. It is proposed an action on different levels linking up clinical attention, psychoeducative and theater workshops. In short, it is noticed that the institution as a set of rules, the professionals as model

Kátia Cristina Tarouquella Brasil, Deise Matos do Amparo, Maristela Munis Gusmão, Roberto Menezes de Oliveira, Maria Ozanete Medeiros, Carlota Novaes \& Lucila Belfort

Núcleo

de estudo e pesquisa da infância

e da adolescência de

risco. Universidade Católica de Brasília.

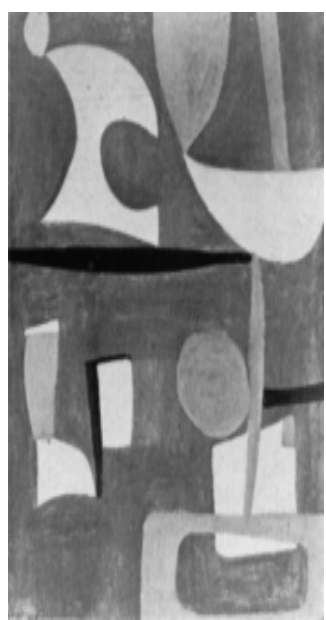
figures and the group as a possibility to be part of a whole, enable to insert adolescents into a process of exchanging their own experiences, encouraging new relationships and enablig a rescue and appropriation of their own stories.

Key Words: Adolescents, situation of risk, interdisciplinary, exclusin.

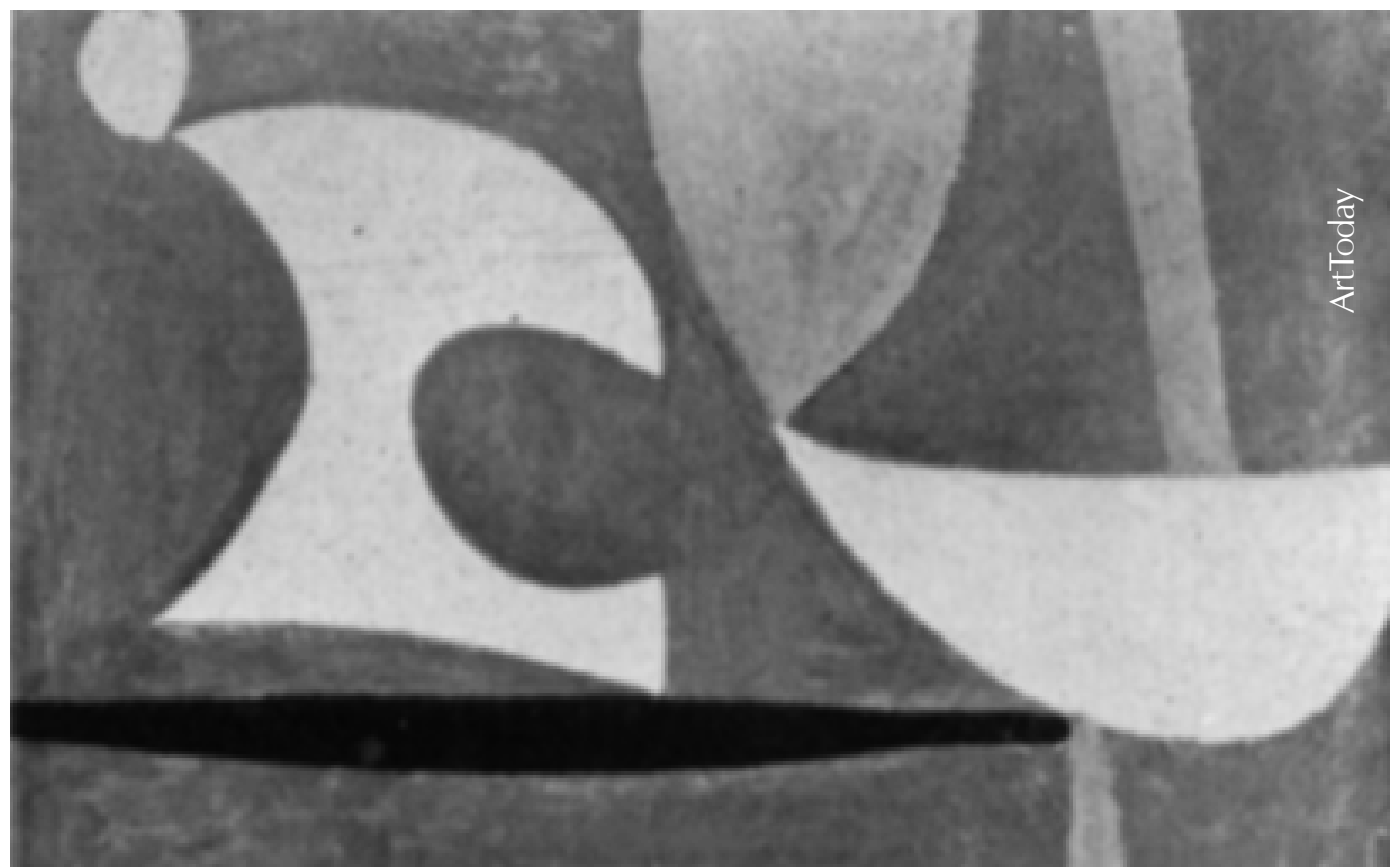

O aumento crescente de crianças, adolescentes e adultos em situação de exclusão social, em particular nos países em desenvolvimento, decorre, em grande parte, da deterioração progressiva das condições sócioeconômicas das camadas de baixa renda e da ausência de políticas públicas pertinentes e eficientes.

Esse perfil revela uma problemática social que exige de todos os segmentos da sociedade modelos de atuação sistematizados e consonantes com as características peculiares das crianças e adolescentes que estão, freqüentemente, expostos a fatores de riscos, como: drogas, prostituição, violência etc. É desnecessário afirmar que esses fatores de riscos comprometem as condições de saúde física e mental desses jovens, prejudicando o seu desenvolvimento e a integração pessoal, familiar e social.

Pensando na urgência dessas questões, o NEPIAR ${ }^{1}$, em parceria com o NATEX ${ }^{2}$, CEMIN $^{3}$ e CDS- 
Ceilândia(DF) ${ }^{4}$ realizaram, em 1998, um programa de intervenção psico-educativo e sóciocultural com adolescentes em situação de risco físico, social e psicológico, que se encontravam em situação de rua, vitimizadas por violência familiar e/ou cumprindo medidas sócio-educativas (Bandeira, Koller, Hutz, \& Forster,1996).

A atualidade da discussão desse tema impõe-nos um compromisso permanente em repensar o papel da interdisciplinariedade na proposta de intervenção. Freqüentemente, os desafios que essa população impõe aos profissionais, levam-nos a questionar os paradigmas constituídos e os modelos de intervenção já estruturados. Partimos do pressuposto da necessidade de acolher esses meninos e meninas, bem como seus familiares, na dimensão social de direito e de cidadania, mas também na dimensão de sujeito psicológico com dificuldades e possibilidades pessoais de mudança. O programa desenvolveu modalidades de intervenção junto a essa população, baseada em estratégias de atenção sóciocultural e psicoeducativas. Nesse contexto, o trabalho se propôs a uma intervenção abrangente, assegurando um modelo de rede institucional integrada a uma equipe interdisciplinar, atuando em diferentes níveis. Assim, a intervenção foi pautada no acolhimento, cujo programa de atendimento se caracterizou pela estruturação de dispositivos clínicos, educativos e lúdicos, diversificados e flexíveis.

\section{Caracterização Psicológica da Problemática}

Pode-se destacar que a intervenção pretendeu abranger o resgate e a apropriação da história subjetiva dos jovens atendidos. Essa temática nos remete ao que é fundamental, a saber, compreender essa população, enfocando não apenas o aspecto das necessidades sociais, mas também o das necessidades afetivas e psicológicas. Assim, a atenção a essa população perpassa questões que se situam, privilegiadamente, em dois campos: a violência, enquanto paradigma relacional, e a problemática da lei enquanto institucionalização do limite.

\section{A Violência Enquanto Paradigma Relacional}

A realidade social e psicológica desses adolescentes é plena de experiências reais de traumatismos. Desse modo, crianças e adolescentes que convivem em seu cotidiano com a violência em suas relações e com a fragilidade dos mediadores da cultura fazem da própria violência um (des)caminho para o vir a "ser", inseridos como receptores e agentes da violência. Nem sempre protegidos pelas instituições sociais, esses jovens encontram no (des)caminho da violência uma via de poder "ser", constitutiva do modo de subjetivação, uma vez que esse modo estrutura os processos de identificação que, por sua vez, são marcados pelo ato em detrimento da significação. $\mathrm{O}$ agir transforma-se, principalmente, em elemento de troca relacional, marcando as relações afetivas fundamentais que serão objeto do jogo identificatório inconsciente, organizador da identidade social e subjetiva. Vale dizer ainda que, paralelo aos atos violentos, esses jovens evidenciam dificuldades na relação com a lei. Destarte, o grande desafio das propostas de acolhimento aos jovens em situação de risco é propiciar que atos de violência possam ser transformados em atos de fala ou em atos simbólicos expressivos, desfazendo a dissonância dos atos violentos e anti-sociais.

\section{A Problemática da lei Enquanto Institucionalização do limite}

Do ponto de vista psicológico, a introdução do limite remete-nos à função paterna, que se realiza no contexto da elaboração da relação mãe-filho com a entrada de um terceiro, o pai. O modo de elaboração e passagem por essa relação triangular terá reflexo na constituição da personalidade, na organização da imagem corporal e no estabelecimento do modo relacional com o outro (Melman, 1995).

Nessa perspectiva, os adolescentes em conflito com a lei apresentam, muitas vezes, dificuldades originárias concernentes às relações mãe-filho, situadas no contexto das dificuldades de resolução da situação edípica. Esse primeiro modelo diádico funciona como ancoragem e marca a constituição dos modelos posteriores de vinculação. Nesse sentido, cabe à mãe designar o terceiro da relação introduzindo a função paterna, representante da lei.

No caso de adolescentes com problemáticas relativas à delinqüência, encontramos na literatura referências que apontam um superinvestimento na relação diádica mãe-filho, na qual a mãe, por meio de um movimento inconsciente e até mesmo consciente, anula o lugar do pai. Tal desqualificação da figura paterna traz como conseqüência uma desqualificação da diferença, do limite e da lei (Sudbrack, 1992).

O sujeito oscila na apropriação da lei simbólica, só restando a ele a passagem ao ato como possibilidade de resolução dos conflitos inerentes a essas relações. A passagem ao ato projeta o jovem para fora de si e de sua família rumo a um terceiro. Todavia, essa projeção por falta de mediadores simbólicos ocorre na concretude do corpo, da violência e da sexualidade (Dupré, 1984).
1 Núcleo de Estudo e Pesquisa da Infância e Adolescência de Risco-Universidade Católica de Brasília

2NATEX - Núcleo de Atenção à Exclusão Social.

3 CEMIM (Centro Miguel Magone).

4 CDS - Centro de Desenvolvimento Social Ceilândia. 
Kátia Cristina Tarouquella Brasil, Deise Matos do Amparo, Maristela Munis Gusmão, Roberto Menezes de Oliveira, Maria Ozanete Medeiros, Carlota Novaes \& Lucila Belfort

Enfim, a problemática dos adolescentes aqui relatada é perpassada pela dimensão do ato. Assim, o agir impôs-se como problemática fundamental que suscitou na equipe a necessidade de repensar estratégias técnicas e metodológicas eficientes de sustentação do trabalho.

\section{Metodologia}

\section{Sujeitos}

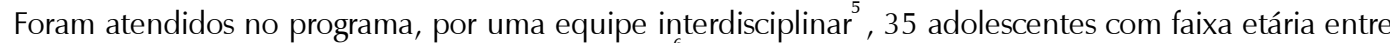
14 e 18 anos incompletos, moradores de Ceilândia ${ }^{6}$. Tais adolescentes encontravam-se expostos à situação de risco físico, social e psicológico - em situação de rua, cumprindo medidas socioeducativas e vitimizados. As crianças e adolescentes em situação de risco vinculavam-se ao programa a partir de dois caminhos possíveis:

a) o trabalho desenvolvido por profissionais da equipe no espaço da rua viabilizava o encaminhamento de jovens em situação de rua para o programa;

b) alguns jovens, em medida de proteção especial e de liberdade assistida que eram encaminhados pelo Centro de Desenvolvimento Social de Ceilândia e pelo CEMIM. Ao entrar no programa, os jovens eram encaminhados a um grupo de acolhimento, que realizava entrevistas individuais e familiares para, posteriormente, engajá-los em uma ou mais das seguintes atividades: oficinas psicoeducativas, atendimento psicoterápico individual, grupo de teatro.

Durante esse percurso, os jovens eram também acolhidos pelo CEMIM e passavam a participar das oficinas profissionalizantes oferecidas pelo referido centro. A profissionalização viabilizava um caminho de inserção dos jovens no mercado de trabalho.

\section{Procedimentos da Coleta de Dados}

\section{Instrumentos}

1.Fichas de relatos das oficinas e do grupo de teatro, nas quais constavam descrição das atividades realizadas; 2.Fichas de relatos de atendimentos clínicos, individualizados, cujo conteúdo discutia-se periodicamente nas reuniões de supervisão clínica;

3.Registro em vídeo dos encontros do grupo de teatro;

4. Registros em fita K7 de reuniões de supervisão.

\footnotetext{
5 Equipe constituída por psicólogos, pedagogos, arteeducadores e estagiários da área de Psicologia, Pedagogia e Educação Física.

6 Cidade situada no Distrito Federal, onde se encontram indices alarmantes de violência.

7 Programa de Semi-liberdade Liberdade Assistida e Proteção Especial.
}

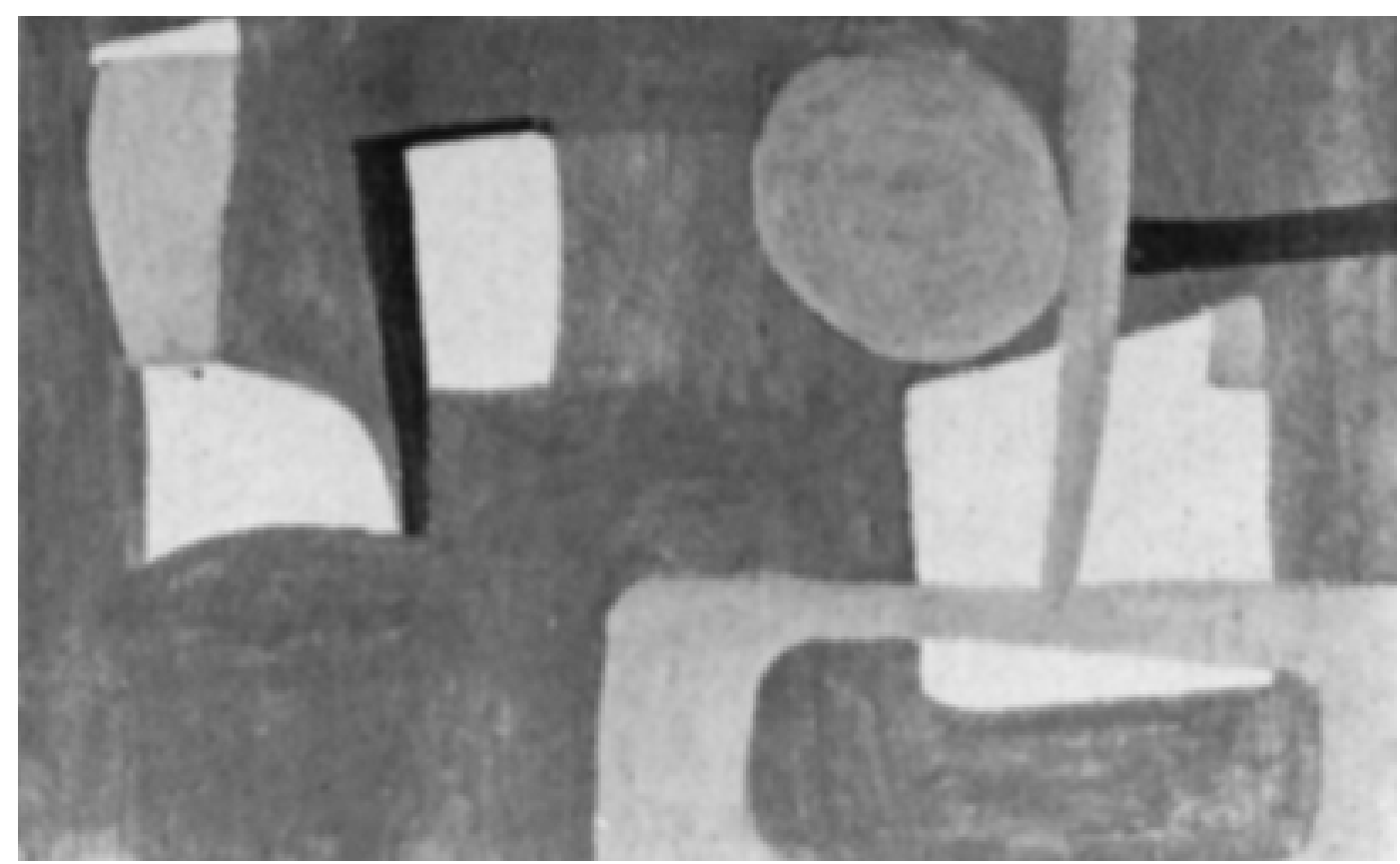


A metodologia do trabalho de intervenção foi composta de estratégias preventivas e de atenção direta. Com isso, buscou-se qualificar a fala desses jovens e seus laços sociais. O programa de intervenção funcionou em três níveis básicos: as oficinas psico-educativas, o grupo de teatro e o atendimento psicoterápico.

Para melhor visualização do percurso do adolescente no programa, apresentamos, a seguir o, Organograma 1.

\section{Organograma do Percurso do Adolescente no Programa}

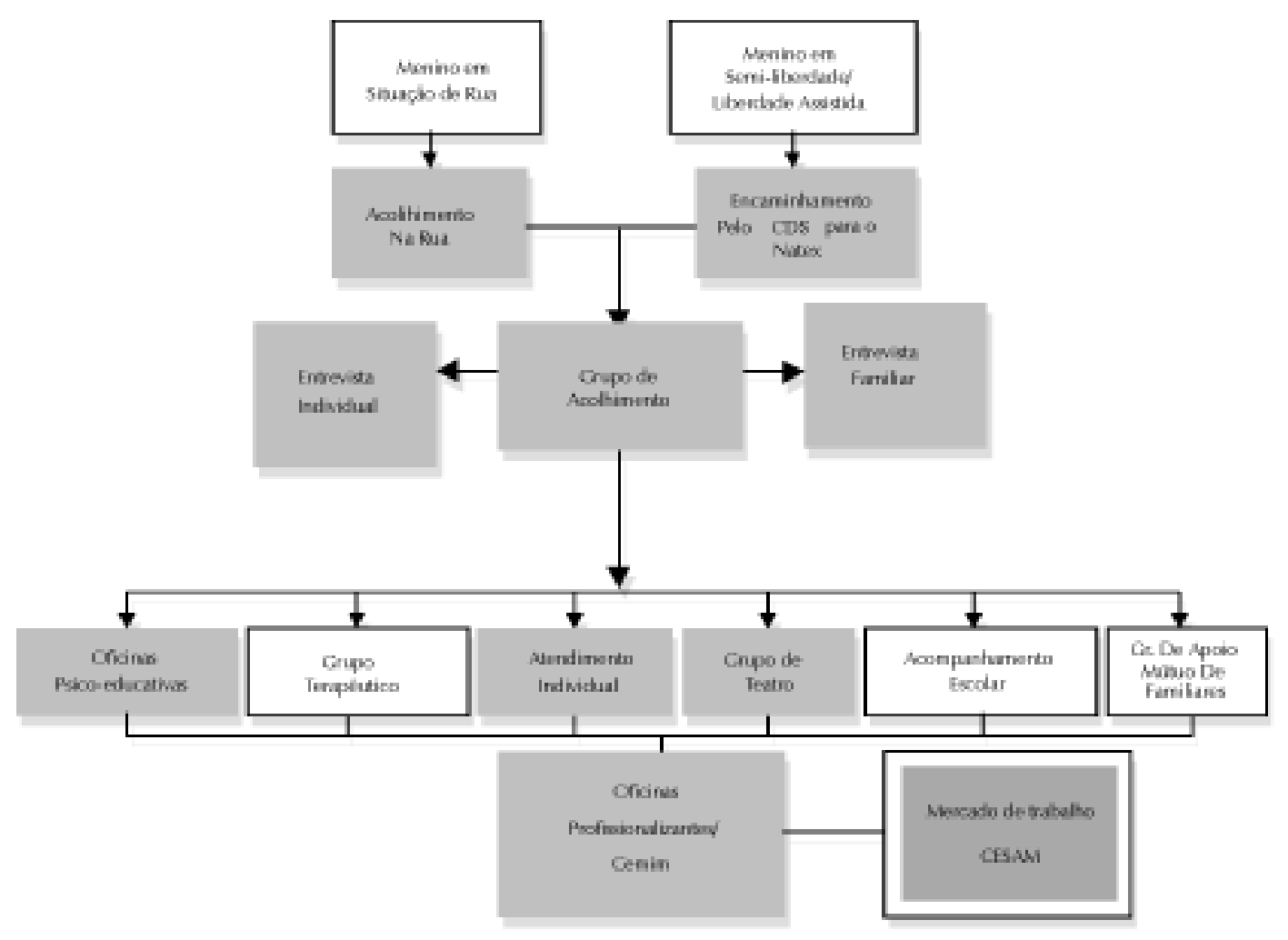

Os atendimentos clínico - psicoterápicos

Os atendimentos psicoterápicos ocorriam individualmente e eram realizados semanalmente pelos psicólogos da equipe. Dentre as maiores dificuldades que essa clínica suscita, elencamos: as ameaças de rupturas, as faltas ao atendimento, as fugas das instituições, a inquietação motora que aparece na transformação dos objetos do setting em "objetos de cena". Sabemos que a impossibilidade de estabelecer uma relação de acolhimento no espaço terapêutico faz com que dificilmente os adolescentes identifiquem no setting terapêutico mecanismos de continência e, por isso, com freqüência, apontam a fragilidade do ambiente para conter a atuação. Os jovens estão constantemente testando as possibilidades do terapeuta em suportar o espanto do confronto com a violência. Cabe ao terapeuta reconhecer essa violência e "demandar pela palavra", explicitando, dessa maneira, o contrato no plano simbólico. Um exemplo dessa situação pode ser identificada no fragmento de atendimento clínico a seguir:

\section{P., 17 anos.}

Sob medida de restrição de liberdade, em semiliberdade, por ter cometido homicídio, latrocínios e assaltos à mão armada, foi encaminhado para atendimento com uma queixa de dependência química (que não foi constatada), proveniente da instituição que acompanha a semi-liberdade. Durante a primeira semana de atendimento, retorna ao regime de internação e passa a vir para o atendimento escoltado.

P., em uma das sessões, fala: "Só tenho dois meses para fugir e resolver uns problemas, matar mais dois e pronto, se eu demorar para fazer isso me complico
Os jovens estão constantemente testando as possibilidades do terapeuta em suportar o espanto do confronto com a violência. 
Kátia Cristina Tarouquella Brasil, Deise Matos do Amparo, Maristela Munis Gusmão, Roberto Menezes de Oliveira, Maria Ozanete Medeiros, Carlota Novaes \& Lucila Belfort

mais. Eu fico pensando que é melhor me arrepender de uma coisa que eu fiz do que de uma coisa que não fiz". A terapeuta intervém, situando a sessão como espaço de fala. Ele repete que só tem dois meses e se cala. A expressão muda, fica tenso e, de repente, se move bruscamente para frente como se fosse levantar. Antes que isso aconteça, a terapeuta pergunta o que houve. "Estou pensando em fugir, saio daqui agora, entro num taxi e sumo".

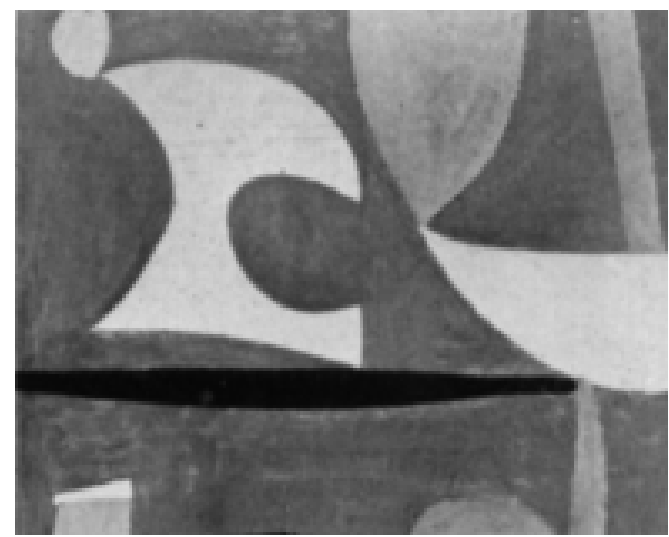

O terapeuta é testado repetidamente na transferência, em sua capacidade para suportar a agressão, para impedir ou reparar a destruição e, sobretudo, para reconhecer o pedido de ajuda no comportamento delinqüente. Do ponto de vista do terapeuta, o que se torna fundamental para o tratamento? Que mantenha sua "plasticidade" (Resnik,1973), em outros termos: usar o estranhofamiliar que o paciente suscita, inserindo-o transferencialmente no campo de trabalho. A transferência, marcada pelas vicissitudes da experiência subjetiva do sujeito, é inerente à prática clínica. A transferência revela toda a complexidade do psiquismo, como os conflitos e as fantasias inconscientes da vida intrapsíquica. A existência do conflito funda a polaridade do psiquismo e revela um sujeito essencialmente marcado por uma rede sistêmica de oposições. Na medida em que o adolescente reativa os traços mnésicos, ele faz um trabalho de associação, de ligação, de simbolização, o que implica dizer que, através da representação, o aparelho psíquico se mostra como um aparelho de transformação, tendo acesso ao simbólico que, como um objeto quebrado, encontra sua unidade (Brasil, 2002).

Nesse contexto, o espaço psicoterápico deve promover um trabalho psíquico a partir da relação transferecial. Entretanto, é fundamental frisar que suportar, acolher e ser continente à atuação desses jovens é apenas uma parte do trabalho psicoterápico. Se o psicoterapeuta espera que o facilitadoras do desenvolvimento afetivo desses

jovens, cabe a ele associar aos mecanismos de continência constantes referências à lei e às interdições que viabilizem a construção de uma nova relação com a realidade e com o meio social.

\section{As Oficinas Psico-Educativas}

As oficinas eram conduzidas semanalmente por uma dupla de profissionais - com pequenos grupos de até 15 adolescentes, inseridos em atividades como: desenho, colagem, modelagem e expressão artística com recursos expressivo e pedagógico. Tais atividades objetivaram criar um espaço de fala, mediado por atividades lúdicas e plásticas. Os temas escolhidos pelos próprios adolescentes enfocavam: família, drogas, sexualidade, violência, temas que retratavam as experiências de vida marcadas por separações, traumatismos e abandonos.

Na relação entre o adolescente e os profissionais, houve espaço para elementos de uma ação educativa com o estabelecimento de uma relação intersubjetiva pedagógica (Bucher, 1989), que tem como objetivo a emancipação do adolescente. Nessa perspectiva, compreende-se o ato educativo como instrumento que possibilita a ruptura com modos habituais de funcionamento, produzindo um efeito psicológico, como nos aponta Lajounquière:

"Em suma, o ato educativo tanto filia sujeitos e conhecimentos quanto abre a possibilidade de que se opere uma ruptura a respeito de si mesmo" (1997, p. 39).

É preciso destacar que os elementos pedagógicos que comparecem nesse trabalho têm uma característica particular. Trata-se de proporcionar melhores condições de aprendizagem e de socialização. Para alcançar esses objetivos, as oficinas demandaram a construção de um processo contínuo de reflexão, necessitando que sua condução se realizasse segundo alguns parâmetros, a saber: sensibilização, criação e reflexão (Medeiros, 1995).

As falas retiradas dos relatos das oficinas psicoeducativas revelaram a busca dos adolescentes pela (re)significação das suas experiências afetivas, cujo movimento podemos observar a seguir, em produção poética de um deles.

\section{16 anos}

"Eu gostaria de saber sobre as drogas, sobre a prostituição sobre as famílias abandonadas, e dos mais abandonado, eu gostaria de saber porque os pais da gente manda a gente embora.

Saber mais sobre o amor, sobre porque hoje em dia as coisas são mais difícil. 
Eu gostaria de saber quando os pais da gente vai embora a gente fica preocupada com eles e eles nem fica preocupado com a gente.

\section{Eu gostaria de saber como os jovens cai na droga tão cedo.}

Eu gostaria de saber porque hoje em dia é pai matando filho e filho matando pai, por que será? Isso não é justo."

Esse espaço de produção permitiu um repensar sobre o seu cotidiano e proporcionou reflexões e alianças com o grupo. As produções estéticas das oficinas permitiram, ainda, uma tentativa de elaboração da auto-imagem e da (re)construção de si, na qual o adolescente pode protagonizar uma outra cena diferente da habitual, de vítima ou de agressor. Ilustra-se esse movimento no seguinte relato:

"M. desenhou um boneco no verso da folha. $\mathrm{Na}$ frente, desenhou uma centopéia cercada de grama. Escreveu: "Eu sou uma centopéia, ando para lá e para cá com minhas cores certeiras, me chamam de feia, feia eu não sou, sou feia por fora e bonita por dentro."

Ao colocar-se como sujeito, o jovem apropria-se do seu corpo e constrói a consciência de si na expressividade relacional (Schilder, 1980).

A oficina psicoeducativa, mesmo não tendo um propósito psicoterapeutico, constituiu-se em um espaço de fala em que temáticas como: violência, família, amizade, amor, entre outras, encontraram um modo de expressão e foram acolhidas pelo grupo. Na oficina de colagem, cujo tema proposto pelo grupo foi a família, as meninas escolheram entre as fotografias de várias revistas imagens que evocassem a idéia de família. Assim, modos de pensar a vida familiar muito variados foram surgindo, como o de J.(15 anos), que recortou a foto de um rapaz na cela de um presídio e falou: "quando os filhos vão para a prisão é muito triste para a mãe", ou como M. (14 anos), que recortou uma família empobrecida em sua casa e quando Ihe foi perguntado o que ela poderia dizer sobre aquela família, a adolescente respondeu: " são felizes porque têm um teto e estão juntos". Na mesma oficina, E. (14 anos) recortou a imagem de um menino machucado e disse: "Um menino machucado porque desobedeceu à mãe e agora está sofrendo e o pai tava bêbado e bateu nele".

Chama nossa atenção a variedade de situações vividas no interior das famílias e a clareza dessas jovens sobre sua história de vida familiar marcada por violência, ruptura e abandono. Os encontros na oficina promoveram um resgate das várias histórias de vida e instauraram um espaço de elaboração da posição de vitimização em relação às famílias de origem e em relação à sociedade. A relação com os outros adolescentes do grupo e com suas histórias fundou uma busca especular, um redobramento identificatório (Froemming, 1999). Nesse cenário, as histórias que se assemelhavam puderam ser significadas.

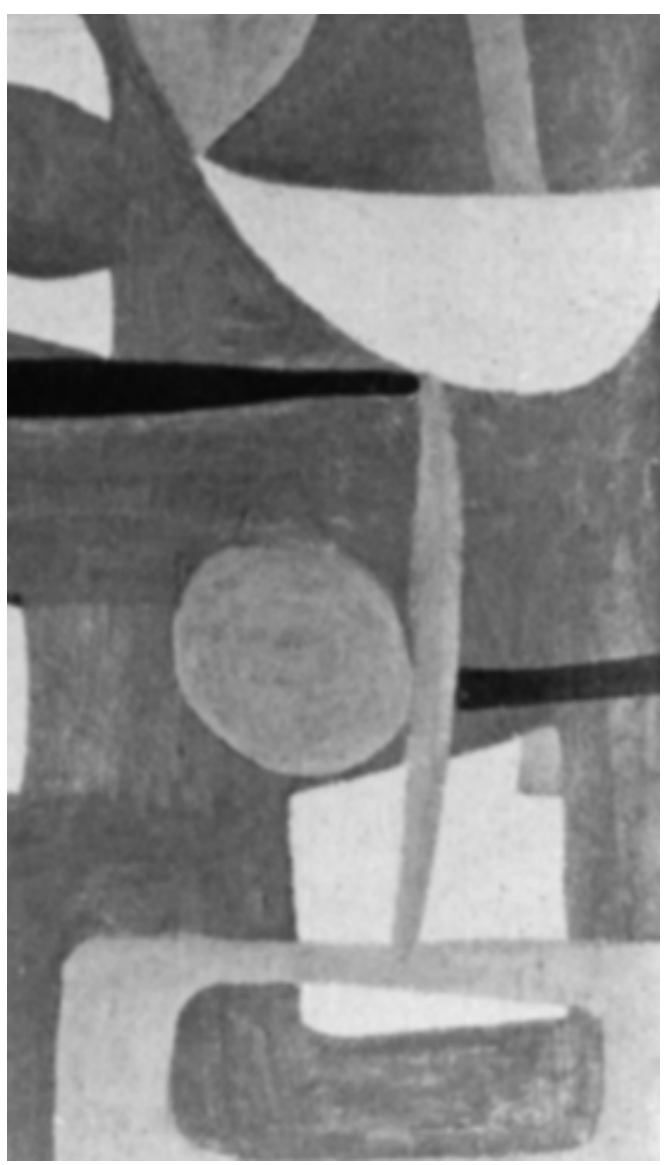

\section{O Grupo de Teatro}

O grupo de teatro mantinha um encontro por semana, com a participação de 35 meninos e meninas. $O$ teatro era conduzido por uma arteeducadora e por duas psicólogas, e contava com a participação de cinco estagiários dos cursos de Psicologia e Pedagogia da Universidade Católica de Brasília. Para dar suporte a esse trabalho, o grupo teatral realizava um encontro semanal de supervisão, coordenado por um psicólogo do programa.

A metodologia de trabalho, permeada pela ludicidade, teve como instrumento técnicas do teatro e do jogo dramático. Inicialmente, a atividade da oficina foi o jogo livre, nele, os 
Kátia Cristina Tarouquella Brasil, Deise Matos do Amparo, Maristela Munis Gusmão, Roberto Menezes de Oliveira, Maria Ozanete Medeiros, Carlota Novaes \& Lucila Belfort

adolescentes criavam livremente as cenas baseadas nas temáticas decididas no grupo. Posteriormente, a atividade na oficina constituiu-se de duas etapas: apropriação da expressão dramática, produção e encenação do texto dramático. Entende-se que o jogo dramático por meio do jogo livre promoveu a emergência de um mundo interno e criou um espaço transicional essencial para que o adolescente pudesse lidar com suas fantasias e seus afetos. Nesse espaço, tudo é permitido vivenciar. Personagens antagônicos travam seus embates em tempo e espaços absolutamente reversíveis.

As atividades teatrais configuraram-se como um meio lúdico de reprodução, imitação e questionamento da realidade, bem como de oportunidade de se promover a emergência de fantasias. Permitiu um aventurar-se no universo social, cultural e imaginário, com um sentido de faz-de-conta e de treino de novas possibilidades de atuação no mundo. Assim, o teatro revelou-se um espaço para lidar com os conceitos morais e éticos, onde o adolescente pode criar regras e legislar sobre elas, além de ter a possibilidade de se colocar no lugar do outro, reconhecendo o respeito às regras do grupo como um instrumento para criação, produção e aprendizagem.

A partir do jogo livre, os adolescentes organizam a dramatização, criando

espontaneamente o texto, as regras para a organização das apresentações e o estabelecimento de parâmetros na expressão dramática.
A condição de produtores culturais permitiu garantir a esses adolescentes um espaço de comunicação com a comunidade, espaço para serem os protagonistas de seus desejos e direitos através da expressão dramática.

A partir do jogo livre, os adolescentes organizam a dramatização, criando espontaneamente o texto, as regras para a organização das apresentações e o estabelecimento de parâmetros na expressão dramática. A riqueza do elemento cênico e lúdico introduzido e articulado com o jogo dramático abre um espaço facilitador do exercício simbólico. Diálogo realizado entre dois adolescentes no jogo livre:

"A: Eu não vou mais fazer o papel do polícia . O policial nunca é respeitado, só falta me bater.

B: Vamos fazer de um jeito que se escute o policial."

Esse diálogo ocorreu após uma tentativa de representação no "jogo livre", a qual não foi levada a termo tendo em vista o fato de os atores não terem respeitado um dos personagens. Nesse exemplo, o policial, que é freqüentemente desqualificado por esses adolescentes, passa a ser visto de um outro modo. Nesse sentido, o exercício cênico facilita, através do lúdico, um redimensionamento da realidade.

O jogo lúdico do teatro e a construção de textos pelos próprios adolescentes permitem, ainda, a expressão da subjetividade, o processo de mediação e o distanciamento das atuações transgressivas.

Dentre outras funções, o jogo dramático cria teias de relações entre os adolescentes dentro do grupo, permitindo atualizar simbolicamente o jogo identificatório. Presenciam-se, assim, dois movimentos: o primeiro refere-se ao recurso às relações entre os adolescentes, que favorecem os mecanismos de identificação grupal, constituídas em um sentido horizontal; o segundo refere-se à busca de identificação com outros modelos ideais fora do grupo, representados muitas vezes nos papéis das figuras de autoridade (pai, padre, paide-santo, professor, policial etc).

\section{Reflexões Finais}

Certamente, em situações sociais complexas, envolvendo crianças e adolescentes em situação de risco, não existe um único modelo de intervenção possível, ao contrário, necessita-se de uma metodologia de intervenção particular que atenda às características peculiares dessa população. Encontramos no modo de funcionamento dos adolescentes as marcas da violência e as tendências ao confronto com a lei. Esse contexto impõe intervenções individuais e grupais com estratégias de atuação interligadas e funções diferenciadas. A implementação de oficinas psicoeducativas, atividades lúdicas, artísticas e atendimentos psicoterápicos se revelou elemento fundamental para a intervenção com adolescentes em situação de risco, trabalho que pretendeu contribuir para a inserção social desses meninos e meninas por meio de uma (re)elaboração subjetiva.

As diversas atividades do programa foram sustentadas por uma equipe interdisciplinar, com a qual os adolescentes estabeleceram relações de apoio, relações pedagógicas e interpessoais subjetivas com caráter clínico (Bucher, 1989), sustentação essa, que acabou por se revelar em estratégia metodológica indispensável à eficiência do trabalho. A diversificação das modalidades de relações permitiu o surgimento de transferências múltiplas dos adolescentes com os diversos membros da equipe. Essa modalidade de vinculação possibilitou e assegurou a continuidade e pertinência do trabalho.

A avaliação do programa revelou que os adolescentes encontraram apoio para um crescimento pessoal, apontando, dessa maneira, para a importância do estabelecimento de diferentes níveis de intervenção que estejam não apenas articulados entre si, mas que possam considerar as dimensões psíquica, pedagógica e cultural, solicitando uma intervenção ampla e interdisciplinar. 
Kátia Cristina Tarouquella Brasil, Deise Matos do Amparo, Maristela Munis Gusmão, Roberto Menezes de Oliveira, Maria Ozanete Medeiros, Carlota Novaes \& Lucila Belfort SHIN QL 03 Conjunto 03 Casa 09 Lago Norte 71505-235 Brasília-DF E-mail:katia@ucb.bre deise@ucb.br

BANDEIRA, D. R., KOLLER, S. H., HUTZ, C. S. \& FORSTER, L. Desenvolvimento Psicossocial e Profissionalização: uma Experiência com Adolescentes de Risco. Psicologia Reflexão e Crítica, 9, 1996, pp. 185207.

BRASIL, K.C. \& DE ALMEIDA, S. Relações de Rua: o Vínculo do Educador com a Criança e o Adolescente em Situação de Rua. Brasília:Universa, 2002.

BUCHER, R. Psicoterapia pela Fala: Fundamentos, Princípios e Questionamentos. São Paulo: EPU, 1989.

DUPRÉ, F. La "Solution"du Passage à l'Acte. Paris: Editions Erès, 1984.

FROEMMING, L.S. De o eu é um Outro Eu: a Amizade como Laço Social. In Jerusalisky. Adolescência: entre o Passado e o Futuro. Porto Alegre: Artes e Ofícios, 1999, pp.113-118.

AJONQUIÈRE, L. Dos "Erros"e em Especial daquele de Renunciar à Educação: Notas sobre Psicanálise e Educação. Estilos da Clínica: Revista sobre a Infância com Problemas. USP: Instituto de Psicologia Ano II (n. 2), 1997.
MEDEIROS, M. O. Tecendo a Teia das Relações na Reconstrução do Currículo: uma Proposta Metodológica. Dissertação de Mestrado. FEUnB, 1995.

MELMAN, C. Haveria uma Questão Particular do Pai na Adolescência? Adolescência. Porto Alegre: Revista da Associação Psicanalítica de Porto Alegre, 5, no 11, 1995, pp. 07-24.

RESNIK, S. Personne et Psychose. Études sur le Langage du Corps. Paris: Payot, 1973.

SUDBRACK, M. F. O. Da Falta do Pai à Busca da Lei: o Significado da Passagem ao Ato Delinqüente no Contexto Familiar e Institucional. Psicologia Teoria e Pesquisa, Brasília, vol 8, 1992, pp. 447-457.

SCHILDER, P. A Imagem do Corpo: as Energias Construtivas da Psique. São Paulo : Martins Fontes, 1980 (originalmente publicado em 1950.) 